\title{
Anxiety and depression in patients with head and neck cancer: 6-month follow-up study
}

\author{
This article was published in the following Dove Press journal: \\ Neuropsychiatric Disease and Treatment \\ 27 April 2016 \\ Number of times this article has been viewed
}

\author{
Yi-Shan Wu' \\ Pao-Yen Lin ${ }^{1,2}$ \\ Chih-Yen Chien ${ }^{3}$ \\ Fu-Min Fang ${ }^{4}$ \\ Nien-Mu Chiu' \\ Chi-Fa Hung' \\ Yu Lee' \\ Mian-Yoon Chong' \\ 'Department of Psychiatry, ${ }^{2}$ Institute \\ for Translational Research in \\ Biomedical Sciences, ${ }^{3}$ Department \\ of Otolaryngology, ${ }^{4}$ Department of \\ Radiation Oncology, Kaohsiung Chang \\ Gung Memorial Hospital, Chang \\ Gung University College of Medicine, \\ Kaohsiung, Taiwan
}

Objective: We aimed to assess psychiatric morbidities of patients with head and neck cancer (HNC) in a prospective study at pretreatment, and 3 and 6 months after treatment, and to compare their health-related quality of life (HRQL) between those with and without depressive disorders (depression).

Materials and methods: Patients with newly diagnosed HNC from a tertiary hospital were recruited into the study. They were assessed for psychiatric morbidities using the Structured Clinical Interview for the Diagnostic and Statistical Manual of Mental Disorders, fourth edition. Their HRQL was simultaneously evaluated using the quality of life questionnaire of the European Organisation for Research and Treatment of Cancer with a specific module for head and neck cancer; and depressed and nondepressed HNC patients were compared by using the generalized mixed-effect model for repeated measurements.

Results: A total of 106 patients were recruited into this study. High rates of anxiety were found at pretreatment, but steadily declined over time (from $27.3 \%$ to $6.4 \%$, and later $3.3 \%$ ). A skew pattern of depression was observed, with prevalence rates from $8.5 \%$ at pretreatment to $24.5 \%$ and $14 \%$ at 3 and 6 months, respectively, after treatment. We found that loss of sense ( $P=0.001)$, loss of speech $(P<0.001)$, low libido $(P=0.001)$, dry mouth $(P<0.001)$, and weight loss $(P=0.001)$ were related to depression over time. The depressed patients had a higher consumption of painkillers $(P=0.001)$ and nutrition supplements $(P<0.001)$. The results showed that depression was predicted by sticky saliva $(P<0.001)$ and trouble with social contact $(P<0.001)$ at 3 months, and trouble with social eating $(P<0.001)$ at 6 months.

Conclusion: Patients with HNC experienced different changes in anxiety and depression in the first 6 months of treatment. Dysfunction in salivation, problems with eating, and problems with social contacts were major risk factors for depression.

Keywords: depression, anxiety, quality of life

\section{Introduction}

Patients with head and neck cancer (HNC) may suffer variable degrees of functional impairment that are related to speaking, swallowing, breathing, taste, and smell, as well as facial disfigurement during treatment and in the illness course. They are at higher risk of having emotional distress than any other form of cancer amid loss of these functions. ${ }^{1,2}$ Emotional disorders might be expected after a diagnosis of cancer and going through a period of enduring adaptation to the illness from weeks to months. Understanding the time course for the impairment of these functions to affect the mood is important for the commencement of early intervention.

A review of the literature revealed that there was wide variation in reported rate of depression in patients with HNC: from $6 \%$ to $48 \%{ }^{3}$ However, this huge discrepancy was mainly because of differences in 1) method of investigation, 2) measurement,
Correspondence: Mian-Yoon Chong;

Yu Lee

Department of Psychiatry, Kaohsiung

Chang Gung Memorial Hospital,

123 Ta-Pei Road, Niao-Sung,

Kaohsiung 833, Taiwan

Tel +88677317123 ext $8753 / 6318$

$\mathrm{Fax}+\mathrm{I} 88677326817$

Email mchong@cgmh.org.tw;

lyu722@cgmh.org.tw 
3) samples, 4) degree of severity or staging of the cancer, and 5) time points of assessment. In general, higher rates of depression were estimated when using patient self-reported questionnaires, where overrating might be seen in most items of somatic dysfunction, particularly patients suffering from a chronic or acute physical illness. ${ }^{4}$ Krebber et al ${ }^{5}$ conducted a meta-analysis, and found that the average rate of depression in HNC patients was $20 \%$ when measured by self-reported questionnaires, but only approximately half of that (11\%) when a diagnostic interview was employed.

Most of these studies were done with patients at 1 year or later, and there have not been many studies on psychiatric morbidity of HNC patients during the early phase of treatment. ${ }^{6,7}$ Following the illness course and treatment, the quality of life (QL) of cancer patients is expected to be affected with the loss of physical and health-related functions. Using a standardized structured interview and validated instrument for the assessment of QL, this study followed patients with newly diagnosed $\mathrm{HNC}$, to 1) assess psychiatric morbidity and its changes, specifically with anxiety and depressive disorders (depression) at pretreatment, 3 months, and 6 months; 2) assess the health-related QL (HRQL) of the patients with HNC; and 3) identify risk factors for depression with various health-related function losses that are associated with HNC.

\section{Materials and methods Subjects}

This was a prospective study of newly diagnosed HNC patients attending the outpatient combined-treatment clinic for HNC at Kaohsiung Chang Gung Memorial Hospital in southern Taiwan between January 2011 and January 2012. The inclusion criteria were newly diagnosed and untreated $\mathrm{HNC}$, not metastatic cancer, and having the ability to verbalize and write. Patients with a history of recurrent HNC or previous malignancy were excluded. In addition, patients with dementia and delirium were also excluded from this study.

\section{Procedures}

This study was approved by the Human Research Ethics Committee of Chang Gung Memorial Hospital (98-3563B). All patients returned written consent before they were included in the study. The psychiatric interview was carried out by a research psychiatrist, while the social and demographic information, as well as QL, was also simultaneously collected by a trained research assistant. The patients were prospectively followed and assessed for their psychiatric morbidities and HRQL before treatment (pretreatment) and at 3 and 6 months.

\section{Structured Clinical Interview for DSM-IV, clinician version}

Psychiatric morbidity were being assessed and made using the Structured Clinical Interview for the Diagnostic and Statistical Manual of Mental Disorders (DSM)-IV (SCID), clinician version, a structured diagnostic interview based on DSM-IV criteria. ${ }^{8}$ The SCID is a clinician-administered, semistructured interview for use with psychiatric patients or with community subjects who are undergoing evaluation for possible psychiatric diseases. Its main framework consists of nine diagnostic modules. Interviewers may choose to eliminate one or more modules to focus selectively on areas of the greatest diagnostic interest. Most sections start with a leading question that allows the interviewer to "skip" the subsequent questions if not met. The SCID is regarded as a gold standard for psychiatric diagnosis, and it was conducted by a senior psychiatrist (YL) with over 25 years of clinical and research experience.

\section{Assessment of health-related quality of life}

The European Organisation for Research and Treatment of Cancer (EORTC) Quality of Life Questionnaire (QLQ) was used to assess QL for cancer patients. It has been translated and validated into 81 languages. Various modules have been developed for disease-specific treatment measurements, and in this study we used the module that is specific to the HNC (the QLQ - Head and Neck [H\&N]-35). ${ }^{9}$ This consists of 35 questions on a 4-point scale ( $1=$ not at all, $4=$ very much), with seven multiple items on pain, swallowing, senses (taste and smell), speech, social eating, social contact, and sexuality, and eleven single items on other health functions related to teeth, mouth opening, dry mouth, sticky saliva, cough, feeling ill, painkillers, nutrition supplements, feeding tube, weight loss, and weight gain. All scales ranged in a transformed score of 0-100. A high score on a symptom scale or single item indicates more severe symptoms or problems. It has been validated using Taiwanese samples with good test-retest reliability and internal consistency. ${ }^{10}$ The EORTC QLQ-H\&N35 has been widely used for studying HRQL in HNC patients in Taiwan and European countries. ${ }^{11,12}$

\section{Statistical analyses}

The demographic characteristics, psychiatric diagnoses, history of substance use (alcohol, smoking, betel nut), clinical staging of cancer, and treatment methods and HRQL were first summarized using descriptive statistics. They were then compared between patients with and without depression using $\chi^{2}$ or $t$-tests. 
With items based on the EORTC QLQ-H\&N35, HRQL was analyzed and compared across time using analysis of variance for repeated measurements. To investigate the effect of depression at each time point on HRQL, a generalized mixed-effect model for repeated measurements was used. This has the advantages over traditional methods, such as last observation carried forward, of including all available data across the follow-up period and providing better estimates under a broad assumption of missing data. Each item of the EORTC QLQ-H\&N35 at pretreatment and 3- and 6-month assessment was explored as the primary outcome, with depression at each time point used as the dependent variable. Post hoc estimation was also applied to compare outcome variables among these three time points. To avoid false positives, Bonferroni correction was used to correct errors made in the multiple testing procedures.

\section{Results}

\section{Characteristics of samples}

Of the 106 patients who were recruited in the study, 93 successfully completed the study. Among those who did not complete the study, three died and ten were unwilling to continue during the follow-up period and excluded. Table 1 shows the sociodemographic and clinical characteristics of the patients, with the majority being males (86\%) and an average age of $52.7 \pm 9.6$ years. Three-quarters of them were married and currently employed, and their mean educational level was $9.9 \pm 3.7$ years. Substance use was commonly seen in these patients, with $63.4 \%$ smoking, $41.9 \%$ drinking alcohol, and $29 \%$ betel-nut chewing. Approximately two-thirds of the patients were diagnosed as having advanced clinical stages of cancer (III and IV), and over half received surgical and/or chemo- and radiotherapy. The time to initial treatment after the diagnosis was $2.2 \pm 1.4$ weeks (Table 1 ).

\section{Psychiatric morbidity}

At the pretreatment evaluation, more than half had one or more psychiatric diagnoses. Because of the small number of patients, we grouped the diagnoses of "adjustment disorder with anxious mood" and "anxiety disorder not otherwise specified" into anxiety disorders (anxiety), and all depressivespectrum disorders into depressive disorders (depression). The prevalence of psychiatric disorders after the regrouping was as follows: anxiety disorders (27.3\%), alcohol-use disorder $(18.9 \%)$, depressive disorders $(8.5 \%)$, and primary insomnia (2.8\%).

During the 6-month period, there were some changes in the distribution of psychiatric morbidities, with the most significant being the consistently and sharply decreasing
Table I Sociodemographic and clinical characteristics of head and neck cancer patients

\begin{tabular}{|c|c|c|}
\hline Variables & Total & Percentage \\
\hline \multicolumn{3}{|l|}{ Sex } \\
\hline Male & 80 & 86 \\
\hline Female & 13 & 14 \\
\hline \multicolumn{3}{|l|}{ Age, years } \\
\hline Mean \pm SD & $52.7 \pm 9.6$ & \\
\hline$\leq 40$ & 8 & 8.6 \\
\hline $4 I-59$ & 64 & 68.8 \\
\hline$\geq 60$ & 21 & 22.6 \\
\hline \multicolumn{3}{|l|}{ Education, years } \\
\hline Mean \pm SD & $9.9 \pm 3.7$ & \\
\hline$<6$ & 27 & 29 \\
\hline $7-12$ & 56 & 60.2 \\
\hline$>13$ & 10 & 10.8 \\
\hline \multicolumn{3}{|l|}{ Marital status } \\
\hline Unmarried & 24 & 25.8 \\
\hline Married & 69 & 74.2 \\
\hline Unemployed & 25 & 26.9 \\
\hline \multicolumn{3}{|l|}{ Substance used } \\
\hline Alcohol & 38 & 41.9 \\
\hline Tobacco & 59 & 63.4 \\
\hline Betel nut & 27 & 29 \\
\hline Week after diagnosis, mean \pm SD & $2.2 \pm 1.4$ & \\
\hline \multicolumn{3}{|l|}{ Cancer staging } \\
\hline Early (stage I-II) & 33 & 35.5 \\
\hline Advanced (stage III-IV) & 60 & 64.5 \\
\hline \multicolumn{3}{|l|}{ Treatment received } \\
\hline Surgery only & 23 & 24.7 \\
\hline $\mathrm{CC} / \mathrm{RT} / \mathrm{CCRT}$ & 43 & 46.2 \\
\hline Surgery + CC/RT/CCRT & 27 & 29.1 \\
\hline
\end{tabular}

Abbreviations: SD, standard deviation; CC, concurrent chemotherapy; RT, radiotherapy; CCRT, concomitant chemoradiotherapy.

rate of anxiety disorders (from $27.3 \%$ to $6.4 \%$ and $3.3 \%$ at pretreatment and 3 and 6 months, respectively). There was not much change in alcohol-use disorders, with rates ranging from $18.9 \%$ to $20.4 \%$. Depression showed a skew pattern, with a rise in the rate after pretreatment $(8.5 \%)$ to three times that at the peak at 3 months $(24.5 \%)$, but gradually receded nearly to the level of initial assessment at 6 months (Figure 1). Psychiatric morbidity with any psychiatric diagnosis declined steadily during the 6-month period (with rates from $54.7 \%$ at pretreatment to $45.8 \%$ at 3 months and $38.7 \%$ at 6 months).

\section{Six-month HRQL}

The 6-month follow-up of HRQL, with results from the assessment on items based on the EORTC QLQ-H\&N35 at pretreatment, 3 months, and 6 months is shown in Table 2 . All except the use of feeding tubes were significant over time, with some differences in patterns of distribution. Similar to the pattern of the rate of depression, patients felt worse and had more pain and higher frequency of taking painkillers in 


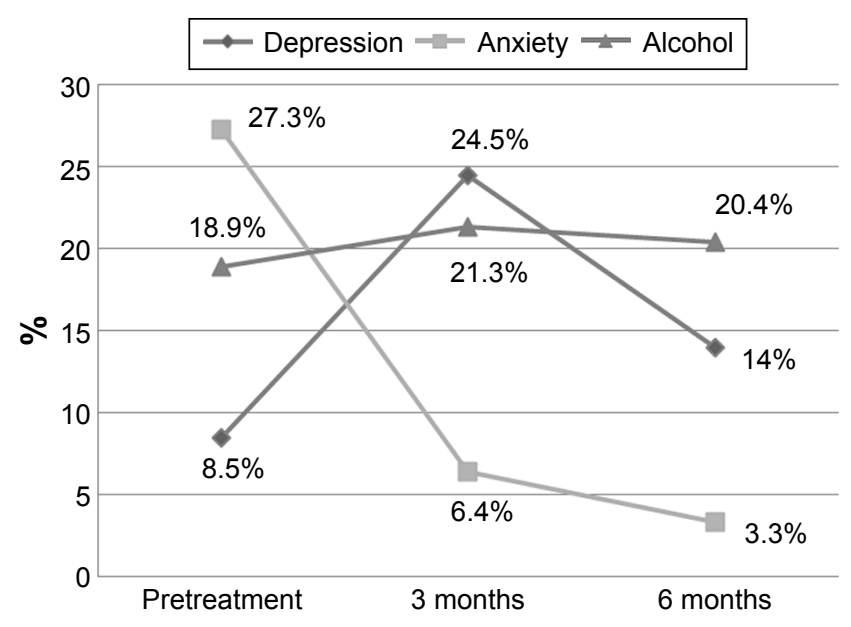

Figure I Psychiatric morbidity of head and neck cancer patients at different intervals.

the first 3 months. Levels returned to approximately the level of pretreatment at 6 months, together with dysfunction of mouth opening, swallowing, sticky saliva, sense and speech problems, trouble with social eating and social contact, and weight loss. The problem with teeth varied over time, but coughing and sexual function decreased with time. Dry mouth persistently increased during the 6-month period, despite a small but steady increment of weight gain.

Table 2 Health-related quality of life, with items from the EORTC QLQ-H\&N35 at pretreatment, 3 months, and 6 months

\begin{tabular}{|c|c|c|c|c|}
\hline \multirow[t]{2}{*}{ Items } & \multirow{2}{*}{$\frac{\text { Pretreatment }}{n=106}$} & \multirow{2}{*}{$\frac{3 \text { months }}{n=94}$} & \multirow{2}{*}{$\frac{6 \text { months }}{n=93}$} & \multirow[t]{2}{*}{$P$-value } \\
\hline & & & & \\
\hline Pain & 5.4 & 6.9 & 4.8 & $<0.00 I^{*}$ \\
\hline Swallowing & 5.2 & 7.8 & 6.5 & $<0.00 I^{*}$ \\
\hline Sense problem & 2.2 & 4.2 & 3.6 & $<0.00 I^{*}$ \\
\hline Speech problem & 3.4 & 5.0 & 4.7 & $<0.00 I^{*}$ \\
\hline $\begin{array}{l}\text { Trouble with } \\
\text { social eating }\end{array}$ & 5.4 & 8.6 & 7.2 & $<0.00 I^{*}$ \\
\hline $\begin{array}{l}\text { Trouble with } \\
\text { social contact }\end{array}$ & 6.0 & 7.3 & 6.6 & $0.001 *$ \\
\hline Sexuality & 13.9 & 3.0 & 3.3 & $0.0029 *$ \\
\hline Teeth & 2.5 & 1.4 & 1.7 & $0.0086 *$ \\
\hline Opening mouth & 1.8 & 2.1 & 1.9 & $0.0012^{*}$ \\
\hline Dry mouth & 1.7 & 2.4 & 2.8 & $<0.00 I^{*}$ \\
\hline Sticky saliva & 1.6 & 2.6 & 2.3 & $<0.00 I^{*}$ \\
\hline Coughing & 2.4 & 1.6 & 1.2 & $0.006^{*}$ \\
\hline Felt ill & 1.7 & 2.1 & 1.8 & $0.005^{*}$ \\
\hline Pain killers & 1.3 & 1.5 & 1.1 & $0.0012^{*}$ \\
\hline $\begin{array}{l}\text { Nutrition } \\
\text { supplement }\end{array}$ & 1.7 & 1.7 & 1.5 & $<0.00 I^{*}$ \\
\hline Feeding tube & 1.5 & 1.2 & 1.0 & 0.3319 \\
\hline Weight loss & 1.3 & 1.6 & I.I & $<0.00 I^{*}$ \\
\hline Weight gain & 1.0 & 1.2 & 1.3 & $0.0034^{*}$ \\
\hline
\end{tabular}

Note: $* p<0.05$.

Abbreviations: EORTC, European Organisation for Research and Treatment of Cancer; QLQ-H\&N, Quality of Life Questionnaire-Head and Neck.

\section{Depression and HRQL}

When comparisons were made between the depressed and nondepressed $\mathrm{HNC}$ patients, there were no significant differences in their sociodemographics (sex, age, marital status, employment, education, and substance use) or clinical characteristics (cancer staging, time to initial treatment, and mode of treatment) (Table 3).

Despite significant changes in HRQL on almost all items of the EORTC QLQ-H\&N35 during the 6-month period, there were some differences between the two groups across time when they were analyzed further using the generalized mixed-effect model. The results showed that over time, loss of functions to sense $(P<0.001)$, speech $(P<0.001)$, sexuality $(P<0.001)$, and dry mouth $(P<0.001)$ were only significantly related to depression, and those with depression had a higher tendency to take painkillers $(P<0.001)$ and nutrition supplements $(P<0.001)$ than nondepressed patients. However, depression was predicted by sticky saliva and problems with social contact at 3 months and social eating at 6 months (Table 4).

\section{Discussion}

This prospective study showed that patients with HNC suffered from variable degrees of psychiatric morbidities during the first 6 months of treatment course. More than a quarter had an anxiety disorder $(27.3 \%)$ at pretreatment, but the rate steadily declined to $3.3 \%$ during the 6 -month period. Depressive disorder, however, did not follow such a pattern, but changed over time and manifested a skew pattern, with a rise in rate during the first 3 months (from $8.1 \%$ to $24.5 \%$ ) and then a gradually return to pretreatment level in later months $(14 \%)$.

When patients were first confronted with the diagnosis of $\mathrm{HNC}$, anticipatory anxiety was commonly seen, along with symptoms of overwhelming information, distractibility, and poor sleep. At this phase, a high rate of anxiety was demonstrated, similar to previous research. ${ }^{13}$ However, once the patients were more adapted to the disease and with the progress of treatment, the rate of anxiety significantly declined. ${ }^{14}$ Early intervention by the team, which included psychiatrists and psychologists, also helped reduce tension and anxiety of the patients.

We used a standardized structured interview in the assessment of psychiatric symptoms and diagnosis (SCID) instead of a self-reported questionnaire. Such a procedure could avoid erroneous rating of symptoms of $\mathrm{HNC}$ for depression or because of the adverse effects of the treatment. For example, physical symptoms with appetite and body-weight loss are common in cancer or during the treatment process. It is thus 
Table 3 Comparisons of sociodemographic and clinical characteristics between head and neck patients with and without depression

\begin{tabular}{|c|c|c|c|c|}
\hline Variables & Depressed, n (\%) & Nondepressed, n (\%) & $\chi^{2} / t$-test & $P$-value \\
\hline \multicolumn{5}{|l|}{ Sex } \\
\hline Male & II (84.6) & $69(86.3)$ & 0.025 & I \\
\hline Female & $2(15.4)$ & II (I3.7) & & \\
\hline \multicolumn{5}{|l|}{ Age, years } \\
\hline Mean \pm SD & $55.1 \pm 9.6$ & $52.3 \pm 9.6$ & 0.961 & 0.339 \\
\hline$\leq 40$ & I (7.7) & $7(8.8)$ & & \\
\hline $4 \mid-59$ & $10(76.9)$ & $54(67.4)$ & 0.505 & 0.777 \\
\hline$\geq 60$ & $2(15.4)$ & $19(23.8)$ & & \\
\hline \multicolumn{5}{|l|}{ Education, years } \\
\hline Mean \pm SD & $8.8 \pm 3.9$ & $10.1 \pm 3.6$ & $\mathrm{I} .207$ & 0.231 \\
\hline$<6$ & $4(30.8)$ & $23(28.8)$ & & \\
\hline $7-12$ & $8(61.5)$ & $48(60)$ & 0.152 & 0.927 \\
\hline$>13$ & I (7.7) & $9(I 1.2)$ & & \\
\hline \multicolumn{5}{|l|}{ Marital status } \\
\hline Unmarried & $4(30.8)$ & $20(25)$ & 0.194 & 0.735 \\
\hline Married & $9(69.2)$ & $60(75)$ & & \\
\hline Unemployed & $4(30.8)$ & $21(26.3)$ & 0.116 & 0.742 \\
\hline \multicolumn{5}{|l|}{ Substance used } \\
\hline Alcohol & $6(46.2)$ & $32(40)$ & 0.175 & 0.675 \\
\hline Tobacco & $10(76.9)$ & $49(61.3)$ & 1.184 & 0.361 \\
\hline Betel nut & $4(30.8)$ & $23(28.8)$ & 0.022 & I \\
\hline Weeks after diagnosis \pm SD & $1.8 \pm 1.1$ & $2.3 \pm 1.4$ & 1.251 & 0.214 \\
\hline \multicolumn{5}{|l|}{ Cancer staging } \\
\hline Early (stage I-II) & $2(15.4)$ & $31(38.8)$ & 2.667 & 0.127 \\
\hline Advanced (stage III-IV) & II (84.6) & $49(61.3)$ & & \\
\hline \multicolumn{5}{|l|}{ Treatment received } \\
\hline Surgery only & $2(15.4)$ & $21(26.2)$ & 0.997 & 0.608 \\
\hline CC/RT/CCRT & $6(46.2)$ & $37(46.3)$ & & \\
\hline Surgery + CC/RT/CCRT & $5(38.4)$ & $22(27.5)$ & & \\
\hline
\end{tabular}

Abbreviations: SD, standard deviation; CC, concurrent chemotherapy; RT, radiotherapy; CCRT, concomitant chemoradiotherapy.

Table 4 Comparison of health-related quality of life between depressed and nondepressed head and neck cancer patients

\begin{tabular}{|c|c|c|c|c|c|c|c|c|}
\hline \multirow[t]{2}{*}{ Items } & \multicolumn{2}{|c|}{ Index, mean (SD) } & \multicolumn{2}{|c|}{3 months, mean (SD) } & \multicolumn{2}{|c|}{6 months, mean (SD) } & \multirow{2}{*}{$\begin{array}{l}\text { Depression, } \\
\text { P-value }\end{array}$} & \multirow{2}{*}{$\begin{array}{l}\text { Time, } \\
P \text {-value }\end{array}$} \\
\hline & $\begin{array}{l}\text { Depressed, } \\
n=9\end{array}$ & $\begin{array}{l}\text { Nondepressed, } \\
\mathrm{n}=97\end{array}$ & $\begin{array}{l}\text { Depressed, } \\
n=23\end{array}$ & $\begin{array}{l}\text { Nondepressed, } \\
n=7 \mid\end{array}$ & $\begin{array}{l}\text { Depressed, } \\
n=13\end{array}$ & $\begin{array}{l}\text { Nondepressed, } \\
\mathrm{n}=\mathbf{8 0}\end{array}$ & & \\
\hline Pain & $5.2(2.2)$ & $5.4(1.7)$ & $7.1(2.8)$ & $6(2.5)$ & $6.2(3.3)$ & $4.6(1.3)$ & & \\
\hline Swallowing & $5.4(3.1)$ & $5.2(2.1)$ & $8.9(3.4)$ & $7.4(3.4)$ & $8.7(2.6)$ & $6.1(2.6)$ & & \\
\hline Sense problem & $2.6(I . I)$ & $2.1(0.7)$ & $4.7(1.9)$ & $4.1(2.1)$ & $3.9(2)$ & $3.5(2)$ & & $<0.001$ \\
\hline Speech problem & $4.6(3)$ & $3.3(0.9)$ & $6.4(3.3)$ & $4.5(2.6)$ & $6.9(3.8)$ & $4.4(2.6)$ & & $<0.001$ \\
\hline $\begin{array}{l}\text { Trouble with } \\
\text { social eating }\end{array}$ & $7(3.4)$ & $5.2(2.3)$ & $12.5(8.1)$ & $7.3(3.4)$ & II.I (2.6) & $6.6(3.2)$ & $<0.00 I(6)^{*}$ & \\
\hline $\begin{array}{l}\text { Trouble with } \\
\text { social contact }\end{array}$ & $8.3(3.6)$ & $5.8(1.8)$ & $9.9(3.4)$ & $6.5(2.3)$ & $11.2(3.6)$ & $5.8(1.7)$ & $<0.001(3)^{*}$ & \\
\hline Sexuality & II.7 (3.6) & I4.2(I.8) & $4(2.6)$ & $2.6(1.7)$ & $5.7(3)$ & $2.9(1.9)$ & & 0.001 \\
\hline Teeth & $3.3(2.2)$ & $2.3(2)$ & $\mathrm{I} .6(\mathrm{I} . \mathrm{I})$ & I.3 (0.7) & $2(1.3)$ & I.7 (I.I) & & \\
\hline Opening mouth & $2.1(1.3)$ & $\mathrm{I} .8(\mathrm{I} . \mathrm{I})$ & $2.4(I)$ & $2(1.1)$ & $2.5(I . I)$ & $\mathrm{I} .8(\mathrm{I} . \mathrm{I})$ & & \\
\hline Dry mouth & $\mathrm{I} .4(0.7)$ & $\mathrm{I} .7(\mathrm{I} . \mathrm{I})$ & $3.1(\mathrm{I} .3)$ & $2.2(1.3)$ & $3.2(\mathrm{I} .3)$ & $2.7(1.3)$ & & $<0.001$ \\
\hline Sticky saliva & $2.6(1.1)$ & $1.5(0.8)$ & $3.4(1.2)$ & $2.4(1.3)$ & $2.4(1.3)$ & $2.1(1.3)$ & $<0.001(3)^{*}$ & \\
\hline Coughing & I.4 (I.I) & $2.5(0.8)$ & $1.6(0.8)$ & $1.6(0.8)$ & $1.5(\mathrm{I})$ & $1.2(0.5)$ & & \\
\hline Felt ill & $2.1(1.3)$ & $1.7(\mathrm{I})$ & $3(1)$ & $1.8(I)$ & $2.7(1.2)$ & $1.6(0.8)$ & & \\
\hline Pain killers & $1.6(1)$ & I.3(0.6) & $1.6(0.5)$ & I.5 (I.4) & I. $.4(0.5)$ & I.I (0.3) & & 0.001 \\
\hline $\begin{array}{l}\text { Nutrition } \\
\text { supplement }\end{array}$ & $2.6(1.2)$ & I.7 (0.7) & $1.8(0.4)$ & $1.7(0.5)$ & I.7 (0.5) & I.5 (0.5) & & $<0.001$ \\
\hline Feeding tube & I.6 (0.5) & I.5 (0.5) & I.2(0.4) & I. $2(0.4)$ & I.I (0.3) & I $(0.2)$ & & \\
\hline Weight loss & I.6 (0.5) & I.3(0.5) & I.8 (0.4) & I.6(0.5) & I.4(0.5) & I.I (0.3) & & \\
\hline Weight gain & I.I (0.3) & I $(0.1)$ & I.I (0.3) & $1.2(0.4)$ & I.I (0.3) & I.3 (0.5) & & 0.001 \\
\hline
\end{tabular}

Note: *Change in health-related quality of life associated with depression at 3 or 6 months.

Abbreviation: SD, standard deviation. 
important to differentiate symptoms of "losing of the function to eat (a symptom of HNC)" with "losing of the desire to eat (a symptom of depression)", where both will eventually result in the loss of body weight. Most self-reported instruments of depressive symptoms nevertheless are not able to make such distinctive differences. ${ }^{4}$ Also, since the SCID assessment was conducted consistently by only one rater, there was less concern about the problem of interrater reliability.

To further assess various symptoms and function loss that were related to the cancer, we employed a questionnaire on HRQL with a module that is specific for HNC: the EORTC QLQ-H\&N35. It was found that there was significant impairment in all items of HRQL during the 6-month period of treatment, except with the use feeding tubes (Table 3). Some of these symptoms might have correlated with depression, ${ }^{12,15,16}$ and this was able to be identified by applying analysis using the generalized mixed-effect model for repeated measurements across time. The results showed that the HNC patients with depression had more significant impairment than nondepressed patients in problems with sense and speech, dry mouth, sexuality, and loss of weight. The depressed patients had higher consumption of nutritional supplements and painkillers. The use of painkillers, especially those with narcotic analgesics, has been reported to have a higher risk of depression. ${ }^{17,18}$

The rates of depression in this sample of HNC patients ranging from $8 \%$ to $25 \%$ are compatible with earlier studies of longer duration. ${ }^{19-23}$ We found that there were no significant differences in sociodemographics (sex, age, marital status, employment, education, and substance use) or clinical characteristics (cancer staging, time to initial treatment, and mode of treatment) between patients with and without depressive disorders, which might indicate that those factors were not the major cause of depression of HNC patients during the treatment course. In the first 3 months of treatment, depression was significantly predicated in patients with dysfunction in salivation with sticky saliva and trouble with social contact. Dry mouth with sticky saliva is regarded as an adverse sign in Chinese medical philosophy that reflects an imbalance of the internal organ systems. ${ }^{24}$ This might have created pessimism in these patients if they had dysfunction in salivation and limitation in the ingestion and chewing of food. As food and eating are intrinsic factors of life and Chinese culture, the loss of such functions among these patients further added to negative thoughts about their vitality and survival. This may partly explain the increasing rate of depressive disorders in the first few months of treatment, together with the fear over the uncertainty of their disease course or even death.
With treatment progress, trouble with social eating was still the main factor related to depression at the 6-month interval. This illustrated the importance of food, eating, and nutrition for these patients, despite impairment of certain physical functions that were related to HNC.

A fifth of the patients abused alcohol, and this rate was consistent throughout the 6-month period. Although alcohol has been regarded as one of the risk factors for $\mathrm{HNC},{ }^{22}$ the rate of alcohol abuse in this study was considered much lower than most reported studies, of 30\%-90\%. ${ }^{25}$ Taiwanese generally have a lower rate of alcoholism than Caucasians, due to a lack of related genes for enzymes that are responsible for metabolizing alcohol and acetaldehyde, ${ }^{26}$ and this could well have accounted for the relatively low prevalence rate of alcoholism in study. In spite of this, $\sim 30 \%$ of these patients had the habit of chewing betel nut. Although it is not related to any mood disorders, chewing betel nut is however carcinogenic to humans, and has been reported to have association with oral/buccal cancer. ${ }^{27}$ Betel nut contains a substance called arecoline, which has proved to contribute to histologic changes in the oral mucosa. Aside from betel-nut habits, it is noteworthy that $>60 \%$ of the patients also smoked. This was not related to mood disorders, but might have harmful effects on health and thus to the disease prognosis. ${ }^{27,28}$

It is believed that one in four terminally ill patients have symptoms of depression, but that up to $80 \%$ of this depression may not be recognized and is thus untreated..$^{29}$ Among the symptoms, loss of sexuality, appetite, body weight, and sleep are also core vegetative symptoms of depression. In our society and across this region, sexual function has often been disregarded, and is regrettably not routinely inquired about or assessed. The awareness of depression, the identification of symptoms, and the initiation of treatment are essential if patients are to be offered optimum palliation of psychological as well as physical symptoms. ${ }^{29}$

\section{Conclusion}

In summary, this study of a 6-month experience of patients with HNC showed that psychiatric morbidities were commonly seen in the early phase of treatment. High rates of anxiety were found before treatment, but had a steadily decline following the treatment course. Depression, on the other hand, demonstrated a skew pattern, with a peak at 3 months declining to pretreatment level at later months. Dysfunction in salivation and problems with social contacts and eating were the three major risk factors for depression at 3 and 6 months, as impairments of sense, speech, dry 
mouth, and sexuality were more significant in the depressed patients who also consumed more painkillers and nutritional supplements.

There are some limitations in this study. First, the sample size was relatively small, and further inferences cannot be made based on the exact anatomical sites that are related to different side effects from treatment (eg, eating and swallowing). Although small in number, patients could be well studied with a prospective design. Second, there was no random selection; a consecutive sampling method was used instead, and it included all cases that fitted the criteria. Third, the follow-up period was relatively short. A longer period is needed to prove the long-term outcome of these functions in relation to depression.

\section{Acknowledgments}

This study was supported by a grant from Kaohsiung Chang Gung Memorial Hospital, Taiwan (CMRPG891321). The authors thank all patients and their families who were involved in the study.

\section{Disclosure}

The authors report no conflicts of interest in this work.

\section{References}

1. Ahn MH, Park S, Lee HB, et al. Suicide in cancer patients within the first year of diagnosis. Psychooncology. 2015;24(5):601-607.

2. Robinson D, Renshaw C, Okello C, Møller H, Davies EA. Suicide in cancer patients in South East England from 1996 to 2005: a populationbased study. Br J Cancer. 2009;101(1):198-201.

3. Archer J, Hutchison I, Korszun A. Mood and malignancy: head and neck cancer and depression. J Oral Pathol Med. 2008;37(5):255-270.

4. Akechi T, Ietsugu T, Sukigara M, et al. Symptom indicator of severity of depression in cancer patients: a comparison of the DSM-IV criteria with alternative diagnostic criteria. Gen Hosp Psychiatry. 2009;31(3): 225-232.

5. Krebber AM, Buffart LM, Kleijn G, et al. Prevalence of depression in cancer patients: a meta-analysis of diagnostic interviews and self-report instruments. Psychooncology. 2014;23(2):121-130.

6. Haisfield-Wolfe ME, McGuire DB, Soeken K, Geiger-Brown J, De Forge BR. Prevalence and correlates of depression among patients with head and neck cancer: a systematic review of implications for research. Oncol Nurs Forum. 2009;36(3):E107-E125.

7. Hammerlid E, Silander E, Hörnestam L, Sullivan M. Health-related quality of life three years after diagnosis of head and neck cancer a longitudinal study. Head Neck. 2001;23(2):113-125.

8. First MB, Gibbon M, Sptizer RL, JBW W. User's Guide for the Structured Clinical Interview for DSM-IV Axis I Disorders: SCID-I. Clinician version. Washington: American Psychiatric Press; 1997.

9. Bjordal K, Hammerlid E, Ahlner-Elmqvist M, et al. Quality of life in head and neck cancer patients: validation of the European Organization for Research and Treatment of Cancer Quality of Life Questionnaire H\&N35. J Clin Oncol. 1999;17(3):1008-1019.

10. Chie WC, Hong RL, Lai CC, Ting LL, Hsu MM. Quality of life in patients of nasopharyngeal carcinoma: validation of the Taiwan Chinese version of the EORTC QLQ-C30 and the EORTC QLQ-H\&N35. Qual Life Res. 2003;12(1):93-98.
11. van Gemert J, Holtslag I, van der Bilt A, Merkx M, Koole R, Van Cann E. Health-related quality of life after segmental resection of the lateral mandible: free fibula flap versus plate reconstruction. J Craniomaxillofac Surg. 2015;43(5):658-662.

12. Leung SW, Lee TF, Chien CY, Chao PJ, Tsai WL, Fang FM. Healthrelated quality of life in 640 head and neck cancer survivors after radiotherapy using EORTC QLQ-C30 and QLQ-H\&N35 questionnaires. BMC Cancer. 2011;11:128.

13. Horney DJ, Smith HE, McGurk M, et al. Associations between quality of life, coping styles, optimism, and anxiety and depression in pretreatment patients with head and neck cancer. Head Neck. 2011;33(1):65-71.

14. Neilson K, Pollard A, Boonzaier A, et al. A longitudinal study of distress (depression and anxiety) up to 18 months after radiotherapy for head and neck cancer. Psychooncology. 2013;22(8):1843-1848.

15. Babin E, Sigston E, Hitier M, Dehesdin D, Marie JP, Choussy O. Quality of life in head and neck cancers patients: predictive factors, functional and psychosocial outcome. Eur Arch Otorhinolaryngol. 2008; 265(3):265-270.

16. Chen ML, Chang HK. Physical symptom profiles of depressed and nondepressed patients with cancer. Palliat Med. 2004;18(8):712-718.

17. Del Fabbro E. Assessment and management of chemical coping in patients with cancer. J Clin Oncol. 2014;32(16):1734-1738.

18. Lai HM, Cleary M, Sitharthan T, Hunt GE. Prevalence of comorbid substance use, anxiety and mood disorders in epidemiological surveys, 1990-2014: a systematic review and meta-analysis. Drug Alcohol Depend. 2015;154:1-13.

19. Gilbert J, Haman KL, Dietrich MS, Blakely RD, Shelton RC, Murphy BA. Depression in patients with head and neck cancer and a functional genetic polymorphism of the serotonin transporter gene. Head Neck. 2012;34(3):359-364.

20. Katz MR, Kopek N, Waldron J, Devins GM, Tomlinson G. Screening for depression in head and neck cancer. Psychooncology. 2004;13(4): 269-280.

21. Kugaya A, Akechi T, Okuyama T, et al. Prevalence, predictive factors, and screening for psychologic distress in patients with newly diagnosed head and neck cancer. Cancer. 2000;88(12):2817-2823.

22. McCaffrey JC, Weitzner M, Kamboukas D, Haselhuhn G, Lamonde L, Booth-Jones M. Alcoholism, depression, and abnormal cognition in head and neck cancer: a pilot study. Otolaryngol Head Neck Surg. 2007; 136(1):92-97.

23. Morton RP, Davies AD, Baker J, Baker GA, Stell PM. Quality of life in treated head and neck cancer patients: a preliminary report. Clin Otolaryngol Allied Sci. 1984;9(3):181-185.

24. Li LX, Tian G, He J. The standardization of acupuncture treatment for radiation-induced xerostomia: a literature review. Chin J Integr Med. Epub 2015 Aug 26.

25. Deleyiannis FW, Thomas DB, Vaughan TL, Davis S. Alcoholism: independent predictor of survival in patients with head and neck cancer. J Natl Cancer Inst. 1996;88(8):542-549.

26. Thomasson HR, Edenberg HJ, Crabb DW, et al. Alcohol and aldehyde dehydrogenase genotypes and alcoholism in Chinese men. Am J Hum Genet. 1991;48(4):677-681.

27. Sharan RN, Mehrotra R, Choudhury Y, Asotra K. Association of betel nut with carcinogenesis: revisit with a clinical perspective. PloS One. 2012;7(8):e42759.

28. Day GL, Blot WJ, Shore RE, et al. Second cancers following oral and pharyngeal cancers: role of tobacco and alcohol. J Natl Cancer Inst. 1994;86(2):131-137.

29. Lloyd-Williams M. Difficulties in diagnosing and treating depression in the terminally ill cancer patient. Postgrad Med J. 2000;76(899): $555-558$. 


\section{Publish your work in this journal}

Neuropsychiatric Disease and Treatment is an international, peerreviewed journal of clinical therapeutics and pharmacology focusing on concise rapid reporting of clinical or pre-clinical studies on a range of neuropsychiatric and neurological disorders. This journal is indexed on PubMed Central, the 'PsycINFO' database and CAS,

and is the official journal of The International Neuropsychiatric Association (INA). The manuscript management system is completely online and includes a very quick and fair peer-review system, which is all easy to use. Visit http://www.dovepress.com/testimonials.php to read real quotes from published authors.

Submit your manuscript here: http://www.dovepress.com/neuropsychiatric-disease-and-treatment-journal 